\title{
1 Solar geoengineering could redistribute malaria risk in developing countries
}

2 Colin J. Carlson ${ }^{1,2,}$, , Rita Colwell ${ }^{3}$, Mohammad Sharif Hossain ${ }^{4}$, Mohammed Mofizur Rahman ${ }^{5}$,

3 Alan Robock ${ }^{6}$, Sadie J. Ryan ${ }^{7,8,9}$, Mohammad Shafiul Alam ${ }^{4}$, and Christopher H. Trisos ${ }^{10,11, *}$

$7 \quad{ }^{1}$ Department of Microbiology and Immunology, Georgetown University Medical Center,

8 Washington, DC 20057, U.S.A.

$9 \quad{ }^{2}$ Center for Global Health Science and Security, Georgetown University Medical Center, 10 Washington DC 20057, U.SA.

$11{ }^{3}$ University of Maryland, College Park, College Park, MD, U.S.A.

$12{ }^{4}$ Infectious Diseases Division, International Centre for Diarrhoeal Disease Research, Bangladesh 13 (icddr,b), Dhaka, Bangladesh.

$14{ }^{5}$ Institute for Technology and Resources Management in the Tropics and Subtropics, Cologne

15 University of Applied Sciences, Cologne, Germany

${ }^{6}$ Department of Environmental Sciences, Rutgers University, New Brunswick, NJ, U.S.A.

$17{ }^{7}$ Quantitative Disease Ecology and Conservation (QDEC) Lab Group, Department of

18 Geography, University of Florida, Gainesville, FL, 32610 USA

$19 \quad{ }^{8}$ Emerging Pathogens Institute, University of Florida, Gainesville, FL, 32610 USA

$20{ }^{9}$ School of Life Sciences, University of KwaZulu-Natal, Durban, 4041, South Africa

$21{ }^{10}$ African Climate and Development Initiative, University of Cape Town, Cape Town, South 22 Africa.

$23{ }^{11}$ Centre for Statistics in Ecology, the Environment and Conservation, University of Cape Town, 24 Cape Town, South Africa

$25 *$ Corresponding authors. Direct correspondence to colin.carlson@georgetown.edu or 26 christopher.trisos@uct.ac.za. 


\section{Abstract}

29 Solar geoengineering is often framed as a stopgap measure to decrease the magnitude, impacts, and injustice 30 of climate change. However, the costs or benefits of geoengineering for human health are largely unknown.

31 We project how geoengineering could impact malaria risk by comparing transmission suitability and 32 populations-at-risk today against moderate and high emissions scenarios (RCP 4.5 and 8.5) with and 33 without geoengineering over the next half-century. We show that if geoengineering deployment cools the 34 tropics, it could help protect high elevation populations in eastern Africa from the encroachment of malaria, 35 but could increase transmission in lowland sub-Saharan Africa and southern Asia. Compared to extreme 36 warming, we also find that by 2070 , geoengineering would nullify a projected reduction of nearly one 37 billion people at risk of malaria. Our results indicate that geoengineering strategies designed to offset 38 warming are not guaranteed to unilaterally improve health outcomes, and could produce regional trade-offs 39 among Global South countries that are often excluded from geoengineering conversations. 
The impacts of climate change are often felt most acutely and personally through human health. Climate change threatens hard-earned progress in infectious disease control and population health during the $20^{\text {th }}$ and early $21^{\text {st }}$ centuries, and most countries' public health infrastructures are likely unprepared to some degree. This is particularly true in developing countries, which already face some of the most severe impacts and the greatest adaptation challenges, often with the least adequate multilateral support. The potential for mass mortality attributable to climate change is increasingly clear and, with existing greenhouse gas emissions mitigation pledges insufficient to keep global warming below $2^{\circ} \mathrm{C}(1)$, radical responses to climate change risks are being considered.

Among these proposed radical schemes is solar geoengineering (also called solar radiation modification, or SRM), whereby the deliberate injection of aerosols into the stratosphere could reflect a small amount of sunlight back to space, cooling Earth. SRM has never been tested outdoors, but large volcanic eruptions are evidence that increasing stratospheric aerosols would cool the planet $(2,3)$. While responses of temperature and precipitation to SRM have been studied in detail, very little is known about possible consequences for humans or ecosystems $(4,5)$. Although there is high confidence in the adverse impacts of global warming - and therefore, motivation to avoid unmitigated warming - the climate of a world with SRM would still differ in notable ways from the current or preindustrial climates. As a result, there is no a priori reason to think that geoengineering would necessarily improve health outcomes uniformly across regions or health burdens. One study has examined the potential impact of SRM on skin cancer and pollutionrelated illness (6), while another has explored health impacts of urban heat stress (7). However, very little is known about possible impacts on infectious diseases, which account for a much higher proportion of global mortality (especially in low- and middle-income countries). This constitutes a major research gap (8), especially given increased attention on SRM and the critical need to consider risks to health in policymaking on climate change.

Of all the possible infectious diseases to prioritize for health impact assessments, many of the best candidates are vector-borne diseases, given their massive global burden and their welldemonstrated (and easily forecasted) climate linkage. Pathogens transmitted by arthropod vectors like mosquitoes or ticks are particularly sensitive to temperature, which determines both their rate of replication in hosts, and the activity and metabolism of their ectothermic (cold-blooded) vectors. Together, these produce a pattern where their transmission responds unimodally to temperature, in a roughly Gaussian response curve (9). Thanks to recent advances in experimental and modeling approaches, scientists can rapidly evaluate these response functions, and confidently identify thermal optima $\left(T_{\text {opt }}\right)$ and outer limits of transmission $\left(T_{\min }\right.$ and $\left.T_{\max }\right)$. Using these parameters, modelers can identify when climatic conditions fall within the boundaries of transmission, and evaluate how the seasonal window of transmission would change in a warming climate $(10,11)$. In the best-quantified cases, temperature can even be explicitly linked to the basic rate of reproduction $R_{0}(T)$, which quantifies the per-infection ability of the pathogen to transmit onwards; projections of $R_{0}(T)$ under different climate scenarios can be used to infer whether particular conditions would support epidemic or endemic transmission.

80 Thanks to these approaches, an emerging body of evidence shows a high confidence link between global climate change and a potential resurgence of vector-borne diseases. By 2070, climate change is expected to increase the global population at risk of the Aedes mosquito-borne dengue 
fever by up to one billion people $(11,12)$, and could plausibly expose a similar or greater number of people to Zika virus if waning population immunity permits another global epidemic (13). In Africa, deaths from yellow fever could increase by $10 \%$ to $25 \%$, depending on warming trajectories and vaccination program coverage (14). But none of these viral infections have a remotely comparable burden to malaria. For comparison, dengue fever is the highest-burden mosquito-borne virus (15). In 2019, the Americas experienced a world-record 3 million reported cases, including at least 1,200 reported deaths. In contrast, the global annual case total of malaria exceeds 200 million, with at least 400,000 deaths almost all caused by the parasite Plasmodium falciparum. Malaria remains the sixth largest cause of death in low income countries; though highly effective control efforts have reduced falciparum malaria prevalence in Africa by half since the turn of the century (16) - making elimination plausible within a generation (17) - the impacts of COVID-19 might jeopardize this progress $(18,19)$. Most available evidence suggests that climate change will favor the expansion of falciparum malaria into southern Africa and highelevation regions of east Africa, and possibly reduce transmission in central Africa and the west African Sahel, though less certainty exists on the second point (20-25).

Comparatively less attention has been paid to Plasmodium vivax malaria, which is responsible for at most $1 \%$ of the total global deaths from malaria, but is responsible for $42 \%$ of all malaria cases outside Africa, and is likely underreported globally (26). In the Americas, $P$. vivax is predominant in most malaria reporting countries, and cases are increasing, including co-infections, according to recent work (27). The collapse of Venezuela's economy, and resulting migration of populations in its wake, following a rapid rise in malaria cases reported from Venezuela, have led to resurgences of both strains of malaria in elimination regions in Latin America (28). This signals that suitable conditions can give rise to re-seeding and re-establishment of transmission in the absence of strict surveillance and control programs (perhaps a bellwether for the importance of climate shifts). The prospect of encroachment of vivax malaria into new areas is particularly troubling, as elimination strategies have largely focused on $P$. falciparum, and basic surveillance may therefore overlook the need to anticipate $P$. vivax, or may simply not have the required testing capacity. Despite these looming risks, vivax malaria is often under-represented in climate work, as comparatively less has been known about its ecology.

Two aspects of malaria transmission make this disease a high priority for risk assessment in solar geoengineering research. First, malaria's burden is measurable enough that it impacts economic growth and population-level mortality; if geoengineering is intended to reduce the health risks of climate change in developing countries, perhaps one of the greatest reductions could be experienced through impacts on malaria. Second, for a pathogen with a mostly tropical burden, malaria is unusually adapted to cooler temperatures, with peak transmission around $25^{\circ} \mathrm{C} \mathrm{(29).} \mathrm{It}$ has been hypothesized that malaria transmission could be inadvertently facilitated by SRM (8), especially given that SRM may cool tropical latitudes relatively more (30). Consequently, when compared to global warming without solar geoengineering, a geoengineering deployment might simply maintain the current burden of disease, or - in a worst-case scenario - inadvertently increase the burden of malaria in developing countries.

We test this idea by investigating scenarios where solar geoengineering is deployed to stabilize average global temperature at 2020 levels against a background of moderate (representative concentration pathway, or RCP, 4.5) or high future emissions (RCP 8.5), and compare this to global warming for the same emissions scenarios without geoengineering. In the Geoengineering 
Model Intercomparison Project (GeoMIP) G3 scenario (31), $\mathrm{SO}_{2}$ aerosols are injected into the stratosphere at the equator with injection increasing gradually over the $21^{\text {st }}$ century to offset warming from RCP 4.5 and stabilize temperatures at 2020 levels. The Geoengineering Large Ensemble (GLENS) scenario (32) injects $\mathrm{SO}_{2}$ to offset warming from RCP 8.5 and stabilize temperatures at 2020 levels, but does this at four locations $\left(30^{\circ} \mathrm{N}, 30^{\circ} \mathrm{S}, 15^{\circ} \mathrm{N}\right.$ and $\left.15^{\circ} \mathrm{S}\right)$ in order to reduce over-cooling of the tropics. Geoengineering could be deployed to offset either all or some amount of global warming, and experts on climate politics and policy have noted the challenge of countries agreeing on an optimal amount of geoengineering. We selected the G3 and GLENS scenarios because they simulate the more "realistic" creation of a stratospheric aerosol layer, deploy geoengineering within emissions scenarios widely used in climate impact assessments, and differ in their injection strategies in tropical regions where the burden of malaria is highest. Other scenarios were not used due to potential layers of additional impacts on malaria that might require dedicated attention (e.g., the potential for termination shocks in the G4 scenario, which might interact with how population immunity changes on the timescale of decades, with complex impacts on disease transmission).

We use these scenarios to predict the transmission boundaries and intensity of falciparum and vivax malaria in their respective regions, and project their shifting transmission and seasonality over the next half-century (2020 to 2070). We limit our analyses to Africa, Asia, and Latin America, where malaria is endemic today, as a subset of the total global shift in favorable temperatures to higher latitudes that has been well-documented for tropical vector-borne diseases. While temperatures may become more favorable for malaria transmission at higher latitudes, healthcare systems in the United States, Europe, and Australia are likely to be strong enough to prevent sporadic importations from establishing malaria transmission in these regions. In contrast, developing countries face the greatest burdens of vector-borne disease, both at present and-with the additional strain of climate change on healthcare systems - in the future.

We used an approach based on the temperature-dependent basic reproduction number $R_{0}(T)$, which has become popular as the thermal biology of mosquito-borne disease has become better understood $(9,29)$. Because arthropod vectors are ectothermic, the processes of mosquito life history and pathogen transmission are very sensitive to temperature, following a simple unimodal curve that can be reconstructed from laboratory experiments and natural transmission data. Given the complexities of real-world transmission, factors like mosquito abundance and human interventions are usually simplified out of this approach, leaving behind a scaled (relative) curve for the temperature-dependent component of $R_{0}$, the basic reproduction number (that is, the percapita growth rate of disease transmission; for a full explanation and equations, see Methods). For this approach, the $R_{0}(T)$ expression denotes suitability for transmission as a function of temperature, scaled between zero and one, derived from a fully-parameterized, life-history explicit, temperature-dependent transmission model of both the vector and pathogen.

This approach cannot necessarily predict total incidence, because major factors such as population density, malaria control, or elimination progress are not included. However, mapping $R_{0}(T)$ can be a first-order proxy of transmission suitability, and, by comparing between scenarios, can indicate where the intensity of transmission and the potential resulting burden of malaria would be higher or lower in different pathways. We make two such comparisons: first, we compare possible futures 
for 2070, with and without SRM deployment; second, we compare a future with SRM deployment against the present-day climate.

We found that across all scenarios, the highest intensity transmission in 2070 will remain where malaria is hyperendemic today, particularly sub-Saharan Africa and the Indian subcontinent (Figure 1). However, we identified several major differences in transmission suitability, which were more pronounced when geoengineering is used to offset warming from RCP 8.5, the high emissions scenario (Figure 2). Compared to climate change without solar geoengineering, we found that SRM might substantially reduce malaria transmission in the Indian subcontinent and the Sahel. Relative reductions are also strong in high-elevation areas like the Andes, the Ethiopian highlands, and the Rift Valley, which have been conventionally viewed as the most vulnerable to malaria encroachment in a warming climate, and are also some of the only regions with an identifiable signal of anthropogenic climate change in recent malaria resurgences.

However, we also found that in many tropical regions - including the Amazon basin, Indonesia, west and central Africa, and the southeast and Atlantic coasts of Africa - solar geoengineering in either the G3 or GLENS scenario could, by stabilizing temperatures at colder levels, increase the relative suitability for malaria compared to a future without geoengineering (Figure $\mathbf{2 A , B}$ ). This is most pronounced in Brazil, Peru, Ecuador, Venezuela and Mozambique, which would all warm under RCP 8.5 so much that they reach a near-zero average suitability for malaria. This reduction is projected to be reversed by SRM in the GLENS scenario, which returns these countries to nearlyoptimal temperatures for malaria by cooling them up to one degree relative to present day temperatures (30).

Finally, we compared 2070 scenarios with geoengineering to malaria suitability in the present day (2020), and found that a future with SRM deployment still looks markedly different from the present day (Figure 2C,D). In particular, in the G3 scenario, most of Africa and part of southeast Asia experiences much higher suitability for malaria transmission, while reductions are projected in most of Latin America. In contrast, most of the tropics become less suitable for malaria in the GLENS scenario compared to the present day, especially the Indian subcontinent, but the Americas experience some elevated risk, as does a hotspot in southeast Asia.

\section{Seasonality and population at risk}

To explore these patterns further, we identified the outer bounds of transmission from the $R_{0}(T)$ curves (that is, $T_{\min }$ and $T_{\max }$ ). For each first year of the decade, from 2020 to 2070, we evaluated whether each day of the year fit within the bounds of transmission $\left(T_{\min } \leq T \leq T_{\max }\right)$, and totaled the number of full days that would be conducive to malaria transmission. Using these maps, we split the tropics into regions where malaria transmission risk was unstable (at least one month was conducive for transmission) or stable (at least half the year). Categories similar to these have been previously used to roughly identify where conditions could permit epidemic and endemic transmission, respectively $(20,33,34)$. Both categories carry risk; today, holoendemic (year-round transmission) malaria places a high burden on children and pregnant women in many hotspots, but episodic malaria epidemics in areas with lower immunity can exhibit high case fatality rates (35). To approximate these relative burdens, we calculated population at risk from stable and unstable transmission in these areas, using future population projections based on the shared socioeconomic pathways paired with our climate scenarios (SSP2-RCP 4.5 and SSP5-RCP 8.5; see Methods). 
In climate change scenarios without geoengineering, much of the world faces increased malaria risk over at least the next decade; in the longer term, regional redistributions of both falciparum and vivax malaria risk are expected throughout the tropics, on the order of hundreds of millions of people. For both RCP 4.5 and RCP 8.5, substantial increases in populations at risk from malaria are projected in east Africa and to a lesser degree central Africa, particularly in high elevation regions where colder temperatures have previously limited malaria transmission. In west Africa, malaria risk also increases, but is dependent on the amount of warming; in RCP 8.5, population exposed to stable transmission risk peaks mid-century and then declines, as much of the region becomes too warm. South and southeast Asia show a similar trend, where warming temperatures in RCP 8.5 lead to massive declines in population at risk ( 200 million people in each region), including some populations shifting from stable into unstable risk. In the rest of the tropics, warming temperatures lead to little change or mild declines in total risk, again with shifts from stable to unstable transmission risk.

We find that solar geoengineering to stabilize planetary temperatures at 2020 levels despite moderate greenhouse gas emissions (the G3 scenario) is projected to initially mitigate population at risk of malaria very slightly, but this effect is short-lived and uncertain, and the total population at risk converges on climate change without geoengineering (RCP 4.5) by mid-century (Figure 3). This largely holds across regions (Extended Data Figures 1 and 2); the most pronounced exception to this global pattern (similar risk with and without geoengineering) is in Africa, where cooler temperatures under G3 are projected to lead to large shifts in population at risk (Extended Data Figure 1). Specifically, in east Africa, compared to RCP 4.5, geoengineering reduces the expansion of the duration of the transmission season, and thereby leads to a smaller increase in population experiencing stable transmission throughout the century. The opposite pattern is projected for west Africa, where geoengineering is projected to elevate stable transmission risk for roughly 100 million people compared to the baseline scenario.

A larger geoengineering deployment to stabilize planetary temperatures at 2020 levels despite high emissions (the GLENS scenario) would nullify a projected reduction of almost one billion more people at the highest risk of malaria in 2070, compared to climate change without geoengineering (RCP 8.5) (Figure 3). We also find strong regional patterns for these projected impacts. For falciparum malaria, the most striking effect is on west Africa: whereas extreme warming begins to decrease malaria endemicity mid-century, avoiding warming through solar geoengineering allows populations at risk to continue growing, leading to a difference of nearly 200 million people by late in the century (Extended Data Figure 3). In both south and southeast Asia, RCP 8.5 leads to massive decreases in stable risk (Extended Data Figure 4). However, averting warming in the GLENS scenario almost entirely nullifies these declines, with a higher population at risk from stable transmission by roughly 200 million people in each region. In east Asia and tropical Latin America, much smaller increases in stable risk are projected due to geoengineering.

Finally, we observed that uncertainty about both baseline climate change impacts and geoengineering impacts showed a tremendous degree of regional variation, which was largely consistent between mid- and high-emissions scenarios. In Latin America and central Africa, changes were highly consistent across climate model runs, and differences between scenarios were minimal. In east and west Africa, we found that differences between climate scenarios were pronounced, but again largely consistent across runs by the end of the century. However, we found that southern Asia - a hotspot of projected changes, and the global hotspot of vivax malaria 
endemicity — showed a tremendous degree of variability, so much so that the differences between the RCP 4.5 and G3 scenario are proportionally much smaller, and essentially impossible to evaluate given model uncertainty (Extended Data Figure 3). This likely reflects a combination of climate model uncertainty and highly aggregated populations, where any one pixel's suitability for malaria may have a marked impact on the total population at risk.

\section{Discussion}

262

Although the proposed geoengineering scenarios we consider are hypotheticals, our results show that geoengineering may not always have desirable health outcomes. Our simulations indicate that proposed geoengineering schemes could lead to local benefits in east Africa, but also large adverse impacts on west Africa and southern Asia. Totaled across regions, the geoengineering scenarios we examined have at best a neutral but patchwork effect on total malaria risk, and at worst could elevate malaria risk relative to climate change without geoengineering. As such, these scenarios illustrate that solar geoengineering could have adverse impacts on health in cases where the burden of infectious diseases lacks a monotonic, positive relationship with warming temperatures. If those diseases are a priority for developing countries' climate policy (as malaria still is in much of the world), we suggest that current proposals for geoengineering might therefore be mismatched to the aim of reducing climate injustice in the health sector. Recent studies based on overshoot scenarios, in which less SRM would be deployed (e.g., (36)), could plausibly lessen the dangers described here, and need to be evaluated with regard to malaria and other health risks.

For health risks with nonlinear responses to temperature (such as vector-borne diseases), this is likely to be a persistent problem, even for geoengineering deployments that only partially offset global warming. Despite their importance, these health risks are comparatively understudied, in part because climate change impact detection and attribution is more difficult than when evaluating other, more direct health impacts of climate (e.g., heat-related deaths), and projections often follow less intuitive patterns. While reduced warming is likely to have some benefits in places where warming is projected to increase risk, our results show that case by case assessment is urgently needed, and regional differences in outcomes must be disaggregated. Without specific research, assumptions that solar geoengineering's health impacts would be intrinsically fair and effective are unsupported, even compared to the most extreme scenarios for climate change. Emissions reduction for climate change mitigation is widely agreed to produce major net benefits across the health sector; climate geoengineering strategies will likely not be as easily weighed, and may be nearly impossible to optimize across all possible or even all major health burdens, including the hundreds of infectious diseases with poorly-understood, non-linear relationships with warming and other climate variables.

This challenge is particularly pronounced given the difficulty of impact assessment for infectious diseases. For example, in this study, we used a relatively simple approach to measuring population at risk and temperature-sensitive transmission. More advanced models that incorporate humanvector transmission dynamics, and other climate variables like precipitation, have become increasingly accessible (37); accounting for these variables will only complicate the non-linear relationships between health outcomes and climate geoengineering interventions. Similarly, the relative priority of malaria is dependent not just on climate change scenarios, but also planetary health scenarios (38). For example, before the COVID-19 pandemic, malaria elimination within a generation was considered plausible, both in terms of epidemiological likelihood and political 
willpower. After COVID-19, the burden of malaria - and many other infectious diseases that have been the subject of large-scale elimination programs - hangs in the balance. Even if COVID-19 is eventually contained, most countries' health systems will remain weakened, and some will face a resurgence of diseases that were well-controlled or even nearing elimination before interventions were disrupted (39-41). In a world that eliminates COVID-19, "builds back better," and recoups these losses, malaria transmission might not be an important issue for climate policy. In a world that fails to do so, with lasting damage from the pandemic, malaria might still be one of the biggest climate related priorities for developing countries, and therefore, one of the greatest potential downsides (or negative repercussions) of solar geoengineering.

Our study underscores the need for involvement and leadership of developing countries throughout climate change policy, including in geoengineering conversations (42). This matters particularly for the health sector, where tradeoffs may emerge between the priorities of developing countries and of those with the greatest influence in climate policy. Vector-borne diseases are largely projected to shift from the tropics to higher latitudes, especially into more affluent countries with stronger health systems, and that increased risk has dominated conversations about their climate change impacts as compared to trends in the rest of the world. For example, dengue incursion into Europe regularly gathers almost as much attention as the record-setting 2019 dengue epidemics in at least a dozen developing countries. Previous work in this space has cautioned against framing the health impacts of climate change around the encroachment of tropical diseases into less vulnerable Global North countries, but this remains a dominant talking point for climate change impacts on vector-borne disease.

320 Debate around solar geoengineering could readily fall into similar traps. While geoengineering might reverse the incursion of tropical diseases into higher latitudes, this framing is oblivious to the reality that the global burden of infectious disease falls disproportionately on the same poorer, tropical and subtropical countries (including small island states) that are syndemically vulnerable to future climate impacts and climate injustice. Framing geoengineering around the health impacts of the "climate emergency" may therefore be undesirable (43), compared to a strategy that meaningfully engages developing countries in terms of their priorities, and develops a comprehensive evidence base of how proposed scenarios will redistribute disease burden between regions. In solar geoengineering research, this means that global involvement in science must not stop with climate modeling; countries' priorities for climate policy, and developing country voices, must be reflected by the impact assessment literature. Only with that greater involvement can the "design problem" of geoengineering meaningfully reflect its impacts on the people most vulnerable to anthropogenic climate change. At the same time, for the health sector - which has a high stake in global climate politics, but little power over it, especially in the regions most vulnerable to epidemics - these kinds of projections will be an important step towards preparing for an uncertain global future. 
Methods

\section{Climate projections}

338 We used two sets of scenarios with different greenhouse gas concentrations and geoengineering deployments. The G3 scenario from the Geoengineering Model Intercomparison Project (GeoMIP) (31) simulates the injection of aerosols into the stratosphere from the equator, starting in 2020 and increasing injection amounts gradually in order to keep global average temperature nearly constant at 2020 levels, despite increasing greenhouse gas concentrations consistent with the moderate mitigation RCP4.5 scenario. The G3 scenario terminates geoengineering in 2070. Therefore, we compared malaria risk in the G3 scenario to climate change in RCP4.5 between 2020 and 2070. The Geoengineering Large Ensemble (GLENS) (32) starts injection of stratospheric aerosols at four locations $\left(30^{\circ} \mathrm{N}, 30^{\circ} \mathrm{S}, 15^{\circ} \mathrm{N}\right.$ and $\left.15^{\circ} \mathrm{S}\right)$ in 2020 in order keep average global temperature constant at 2020 levels, despite increasing greenhouse gas concentrations from RCP8.5, a no mitigation scenario. We compared malaria risk in the GLENS scenario to RCP8.5 between 2020 and 2070 .

We used projections of near-surface daily air temperature and monthly precipitation from the HadGEM2-ES model for both the G3 and RCP4.5 scenarios and from the CESMI(WACCM) model for GLENS and RCP8.5. We selected these climate models and scenarios in part because, while earlier geoengineering simulations merely turned down the solar constant, both models in this study simulated the more "realistic" creation of a stratospheric aerosol layer. Three ensemble members (that is, simulations beginning with slightly different initial conditions) were used from each climate model for each scenario in order to account for natural variability of the climate system, allowing evaluation of the extent to which differences in malaria risk between scenarios with and without geoengineering are forced or random. (Because both the G3 and GLENS scenarios are accompanied by only three natural climate runs, we paired them with the first three ensemble runs generated by each geoengineering simulation, for a balanced study design.) All climate variables were regridded to one-degree spatial resolution using bilinear interpolation.

\section{Malaria Transmission Models}

Because mosquitoes are ectothermic, mosquito-borne diseases are incredibly temperaturesensitive, and their global distribution and burden is shaped by the underlying landscape of climate. The transmission of mosquito-borne disease is usually depicted as a unimodal response to temperature, with an optimum temperature for transmission bounded above and below by critical limits. When ambient temperature is within those bounds, vectors are considered competent enough to transmit diseases. "Transmission" is most readily depicted as a relative basic reproduction number $R_{0}(T)$, which can be rescaled between zero and one for convenience, and is used to identify the minimum, optimum, and maximum temperature for transmission. This can be parameterized with a combination of seven ecological traits (biting rate $a$, vector competence $c$, parasite development rate $P D R$, mosquito development rate $D$, egg-to-adult mosquito survival $s$, adult mosquito mortality $\mu$, and egg laying per day $E$ ), using a set of formulas based on the canonical Ross-Macdonald model of malaria transmission. By fitting nonlinear curves to each of the seven traits, a total transmission $R_{0}(T)$ can be derived: 


$$
R_{0}(T) \propto \sqrt{\frac{a^{2} c s D E \exp \left(\frac{-\mu}{P D R}\right)}{\mu^{3}}}
$$

The total value of this formula is then scaled between zero and one. The shape of that curve varies based on each of the component traits, and ultimately differs across different disease transmission systems due to differences in both vector life history and pathogen ecology.

While the $R_{0}(T)$ approach does not inherently predict the incidence of disease- - which is heavily influenced by other factors, like human and vector density, contact rates, and control measures, and also confounded by diagnostics - it does validate well against prevalence data in comparisons. For climate change impact assessment, the $R_{0}(T)$ approach can be used as a first-principles way to connect warming temperatures to future expansion and redistribution of risk. This approach has been previously used to project the future distribution of risk for malaria $(10,20,22)$, dengue fever (11), and Zika virus (13), among many other vector-borne pathogens.

Basic understanding of thermal ecology is still being developed for malaria. Best understood is Plasmodium falciparum malaria, the more severe form of the disease largely transmitted by Anopheles gambiae species complex mosquitoes in Africa. A foundational study (29) showed that malaria has a much lower optimal temperature than was originally believed based on observational data, with an optimal temperature around $25^{\circ} \mathrm{C}$. Comparatively less is known about $P$. vivax, the less severe form endemic to southern Asia and the Americas; previously, this pathogen reached much higher latitudes, and has been conventionally viewed as more cold-adapted than $P$. falciparum. More recent work suggests this may be deeply interlinked with vector biology, and that the lower critical temperatures of $P$. vivax may in fact be largely driven by the An. stephensi mosquito in south Asia (44); comparatively less is known about $P$. vivax in the Americas.

To map malaria, we used an approach originally developed over the last decade $(22,45)$, which identifies areas suitable for malaria transmission based primarily on temperature. Following (45), we used daily gridded climate data and mapped the number of days in each pixel that were fully within the thermal bounds of transmission based on $R_{0}(T)$. Adapting the approach used by previous studies, we masked out deserts based on the most commonly used definition in the geosciences (250 $\mathrm{mm}$ annual precipitation or less). This step accounts for the possibility that some areas are too arid for mosquitoes to complete their reproductive cycle in some areas (though some species, like An. stephensi, are container breeders like the yellow fever mosquito Aedes aegypti, and may persist in areas with the help of human structures). Beyond this masking step, the presence or absence of Anopheles vectors only minimally limit this approach; roughly a hundred species of Anopheles are capable of transmitting malaria on every inhabited continent, and competent vectors occurred throughout the regions we were considering (46). However, it remains possible that mosquito range shifts - or possible coevolution between mosquitoes and parasites in the futurecould change the reliability of this first order proxy, as could the expansion of P. vivax and An. stephensi mosquitoes in eastern Africa, or any other state shifts in malaria control.

To reflect differences in vector-pathogen systems across landscapes, we used three separate transmission models by region (see below). In sub-Saharan Africa, we used the canonical estimates of Plasmodium falciparum transmission by An. gambiae $\left(17\right.$ to $\left.34^{\circ} \mathrm{C}\right)$, based on (29). Several 
studies since have proposed adjustments to these limits, based on further mathematical modifications of the $R_{0}(T)$ model (e.g., the inclusion of daily thermal variation through an integral process), but we chose to stay with these estimates as the most similar to the experimental limits that have been observed for transmission (which has been seen as low as $16^{\circ} \mathrm{C}$ ). For Plasmodium vivax in southern Asia, we used a more recent estimate by (44), which assumes that transmission by $A n$. stephensi occurs between $15.7^{\circ} \mathrm{C}$ and $32.5^{\circ} \mathrm{C}$. For $P$. vivax in the Americas, where at least ten Anopheles vectors have been identified as transmitters of malaria (47), as there is little published thermal ecology for individual vector-parasite pairs, we assumed based that local vectors were comparable to An. gambiae in their thermal ecology, and that the bounds of vivax transmission were $19.4^{\circ} \mathrm{C}$ to $31.6^{\circ} \mathrm{C}$.

We identified populations at risk by dividing the world into a set of regions modified from the Global Burden of Disease study regions $(11,13,48)$, and estimated the population at risk from falciparum and vivax malaria based on the thermal bounds and precipitation cutoffs explained above. These regions have previously been used for impact assessment models $(11,13)$, but we have made two slight adjustments that primarily reflect the global status of malaria elimination and burden. Given that the Caribbean has eliminated malaria, we reassigned Belize to Latin America (Central), and reassigned Guyana, French Guiana, and Suriname to Latin America (Tropical). Similarly, given the high burden of malaria on the entire island of New Guinea, which is split by the boundary between Indonesia and Papua New Guinea, we regrouped Papua New Guinea with Asia (Southeast).

We paired malaria regions with the dominant form of malaria in each. In Africa, the more severe $P$. falciparum is the dominant form of malaria, while $P$. vivax is endemic to South America, southern Asia, and - though rarer than falciparum - parts of east Africa. We therefore modeled falciparum risk in four regions of Africa (West, East, Central, \& Southern), and modeled vivax risk in six regions of Asia (East, South, and Southeast) and Latin America (Central, Tropical, and Andean). We focused on falciparum risk for East Africa given both the more severe presentation, and the difficulty of comparing the relative burden of the two given diagnostic challenges.

To estimate future populations at risk, we paired representative concentration pathways (RCPs) with shared socioeconomic pathways (SSPs) using the conventional scenario matrix, which identifies more and less plausible combinations of global development strategies and greenhouse gas emissions reductions (49). Given that RCP and geoengineering scenarios were paired, we chose to keep consistent SSPs between baselines and geoengineering scenarios. In practice, this led to two experiments: (1) RCP4.5 (some mitigation) paired with SSP2 versus G3 paired with SSP2; and (2) RCP8.5 (minimal mitigation) paired with SSP5 versus GLENS paired with SSP5. For each climate-SSP pairing we used three climate model runs. SSP data were taken from the SEDAC Global One-Eighth Degree Population Projection Grids (50), which include urban and rural population projections for each decade between 2010 and 2100.

To project populations-at-risk from malaria, we rasterized region boundaries (using a fractional approach to proportional area, rounded to the nearest $1 \%$ of a grid cell), and then summed the populations in every grid cell that fell within thermal bounds and precipitation cutoffs. Temperature cutoffs were applied at the daily level and summarized for each pixel, and classified 
medRxiv preprint doi: https://doi.org/10.1101/2020.10.21.20217257; this version posted October 25, 2020. The copyright holder for this preprint (which was not certified by peer review) is the author/funder, who has granted medRxiv a license to display the preprint in perpetuity.

It is made available under a CC-BY-NC-ND 4.0 International license .

459 into two strata of risk: unstable or epidemic risk (over 30 days and under 180 days, or 1-6 months 460 of the year), and stable or endemic risk (over 6 months of the year). These classifications are 461 adapted from prior work that has stratified based on monthly temperature cutoffs, but have been 462 adapted to using daily-level climate data. The split can be thought of as indicative of a first-order 463 stratification of burden: most of the burden of malaria, especially mortality, is clustered in places 464 where malaria is endemic or hyperendemic. However, epidemics can be particularly severe in 465 places where malaria is rare, and population immunity is therefore lower (e.g., high-elevation 466 communities in east Africa, or near-elimination communities in Latin America). 
medRxiv preprint doi: https://doi.org/10.1101/2020.10.21.20217257; this version posted October 25, 2020. The copyright holder for this preprint (which was not certified by peer review) is the author/funder, who has granted medRxiv a license to display the preprint in perpetuity.

It is made available under a CC-BY-NC-ND 4.0 International license.

\section{Author Contributions}

468 CJC and CHT designed experiments and CJC performed analyses. All authors contributed to the 469 conceptualization, writing, and editing of the manuscript.

\section{Acknowledgements}

471 This work was supported by funding from the Solar Radiation Management Governance Initiative 472 (SRMGI) Developing Country Impacts Modelling Analysis for Solar Radiation Management 473 (DECIMALS) grant program. CHT was supported by the FLAIR Fellowship Programme: a 474 partnership between the African Academy of Sciences and the Royal Society funded by the UK 475 Government's Global Challenges Research Fund. Alan Robock supported by NSF grants AGS4761617844 and AGS-2017113. We thank the UK Hadley Centre for contributing their simulations 477 to Earth System Grid, from which we downloaded the output. Special thanks are extended to 478 Simone Tilmes and Daniele Visioni for assistance with climate data, and to Andrew Parker, Peter 479 Irvine, Ben Kravitz, and John Moore for thoughtful input and comments on the study. icddr,b is 480 grateful to the Government of Bangladesh, Canada, Sweden, and the UK for providing 481 core/unrestricted support. 
medRxiv preprint doi: https://doi.org/10.1101/2020.10.21.20217257; this version posted October 25, 2020. The copyright holder for this preprint (which was not certified by peer review) is the author/funder, who has granted medRxiv a license to display the preprint in perpetuity.

It is made available under a CC-BY-NC-ND 4.0 International license.

Figures

Figure 1. Thermal suitability for malaria today and in futures with and without solar geoengineering. Transmissibility measured by a scaled $R_{0}(T)$, which ranges between zero and one

(A) RCP 4.5 present day (2020)

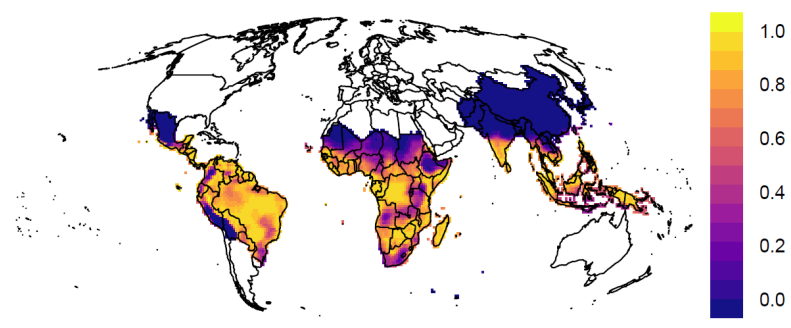

(C) RCP 4.5 scenario (2070)

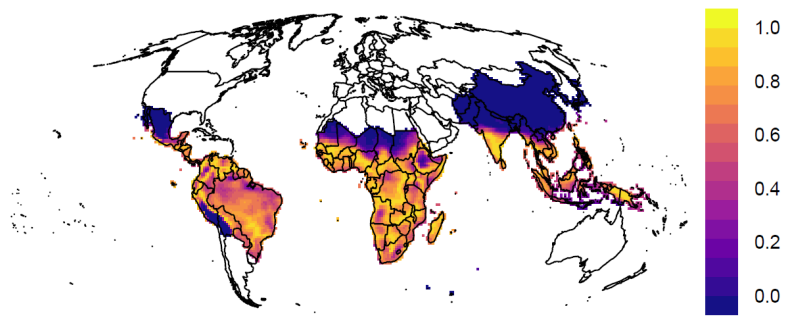

(E) G3 scenario (2070)

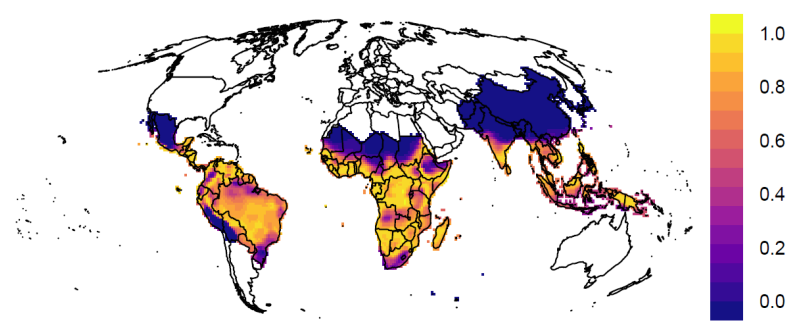

(B) RCP 8.5 present day (2020)

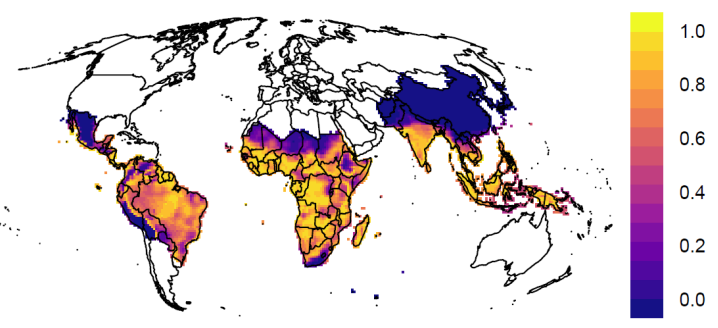

(D) RCP 8.5 scenario (2070)

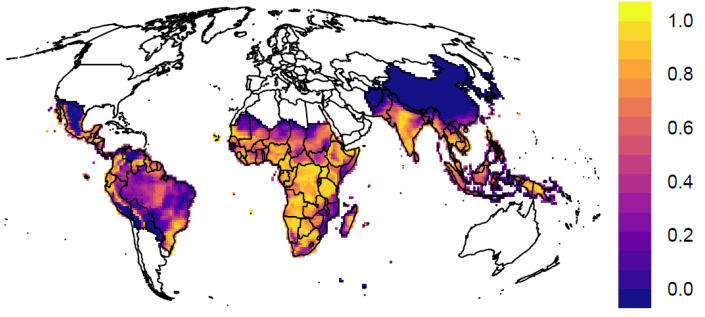

(F) GLENS scenario (2070)

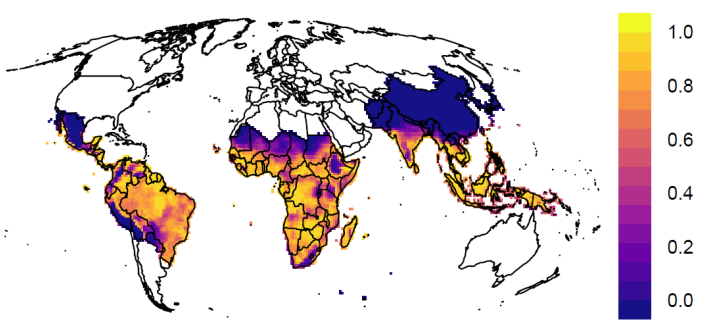


medRxiv preprint doi: https://doi.org/10.1101/2020.10.21.20217257; this version posted October 25, 2020. The copyright holder for this preprint (which was not certified by peer review) is the author/funder, who has granted medRxiv a license to display the preprint in perpetuity.

It is made available under a CC-BY-NC-ND 4.0 International license .

Figure 2. Impacts of solar geoengineering on malaria transmission. Values are given as the difference in scaled $R_{0}(T)$ between different scenarios, where a higher positive value indicates that the geoengineering scenario creates greater thermal suitability for malaria transmission. Geoengineering scenarios are compared to future scenarios with climate change (A, B), and compared to the present day (using baseline RCP scenarios).

(A) G3 versus RCP 4.5 (2070)

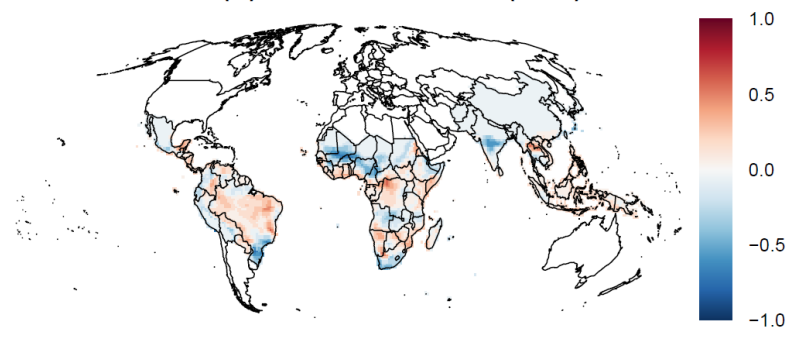

(C) G3 (2070) versus present day (2020)

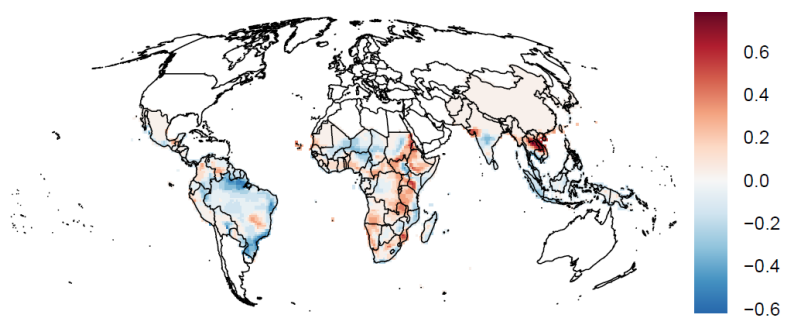

(B) GLENS versus RCP 8.5 (2070)

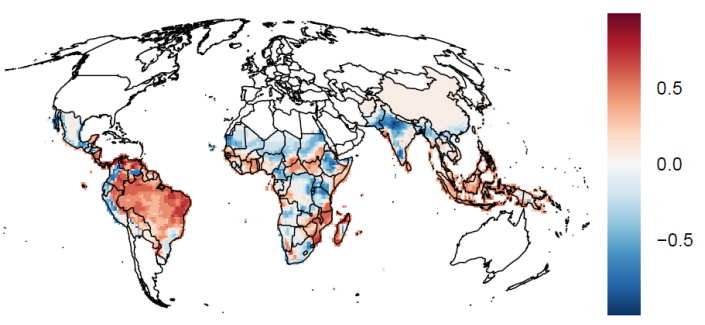

(D) GLENS (2070) versus present day (2020)

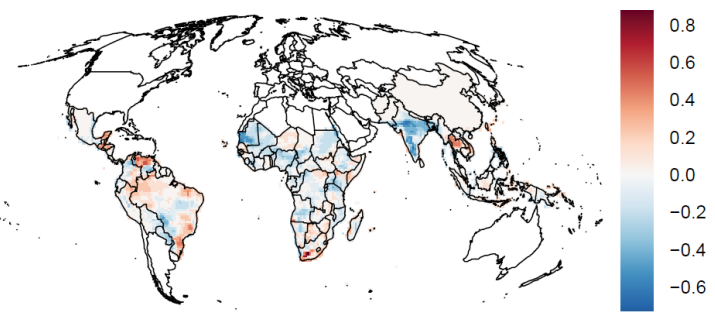


medRxiv preprint doi: https://doi.org/10.1101/2020.10.21.20217257; this version posted October 25, 2020. The copyright holder for this preprint (which was not certified by peer review) is the author/funder, who has granted medRxiv a license to display the preprint in perpetuity.

It is made available under a CC-BY-NC-ND 4.0 International license .

Figure 3. Global population at risk from malaria. Population at highest risk is given as the Scenarios are paired between baseline scenarios and geoengineering scenarios, where SRM

501 deployment is modeled in the G3 scenario relative to RCP 4.5, and in the GLENS scenario

502

503 relative to RCP 8.5. Each value is averaged across three scenario-specific runs from a climate

504 model ensemble.
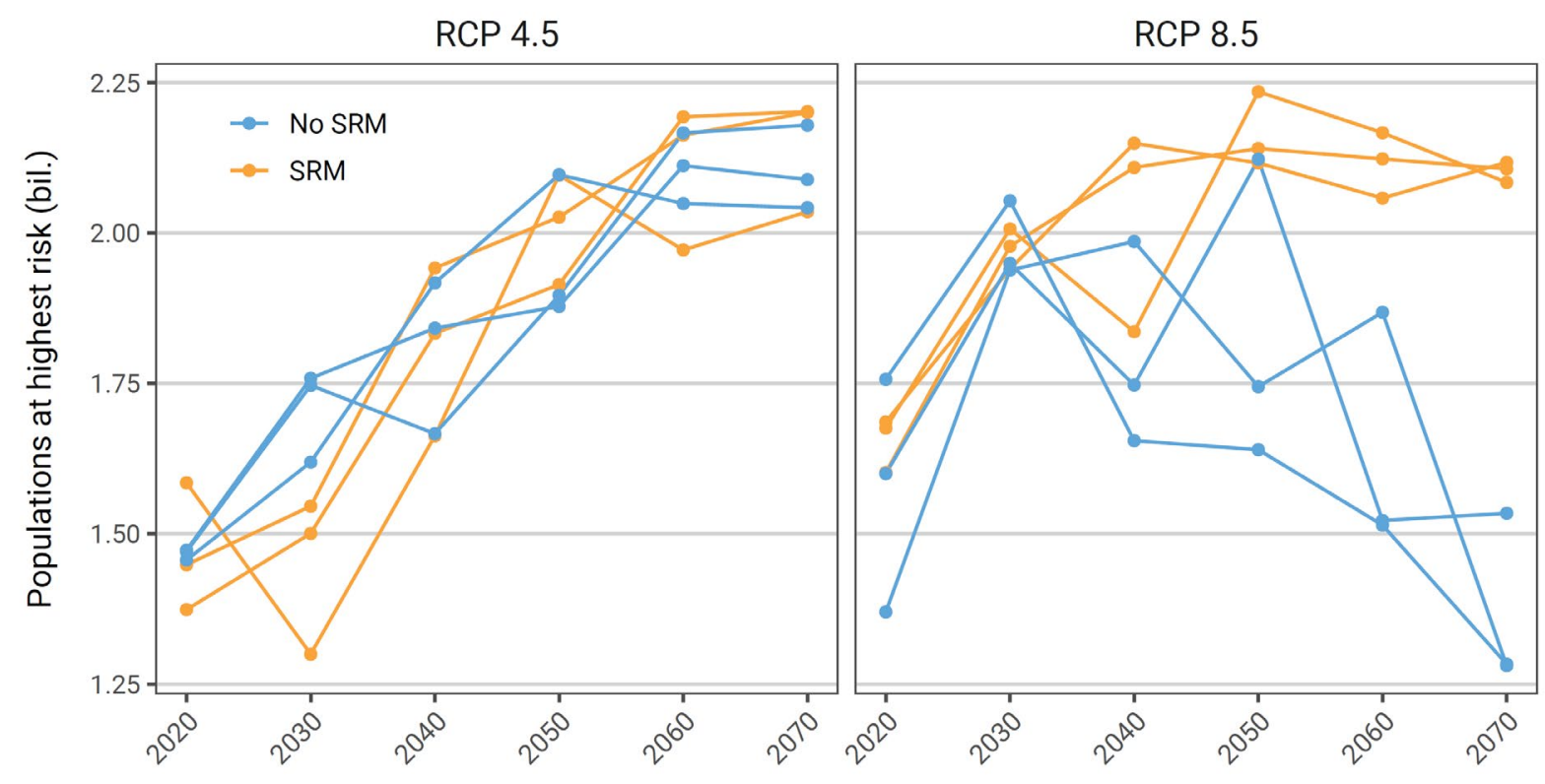
medRxiv preprint doi: https://doi.org/10.1101/2020.10.21.20217257; this version posted October 25, 2020. The copyright holder for this preprint (which was not certified by peer review) is the author/funder, who has granted medRxiv a license to display the preprint in perpetuity.

It is made available under a CC-BY-NC-ND 4.0 International license .

507 Transmission risk is split below, into stable risk (left) and unstable risk (right). Populations at risk 508 are reported in millions of people.
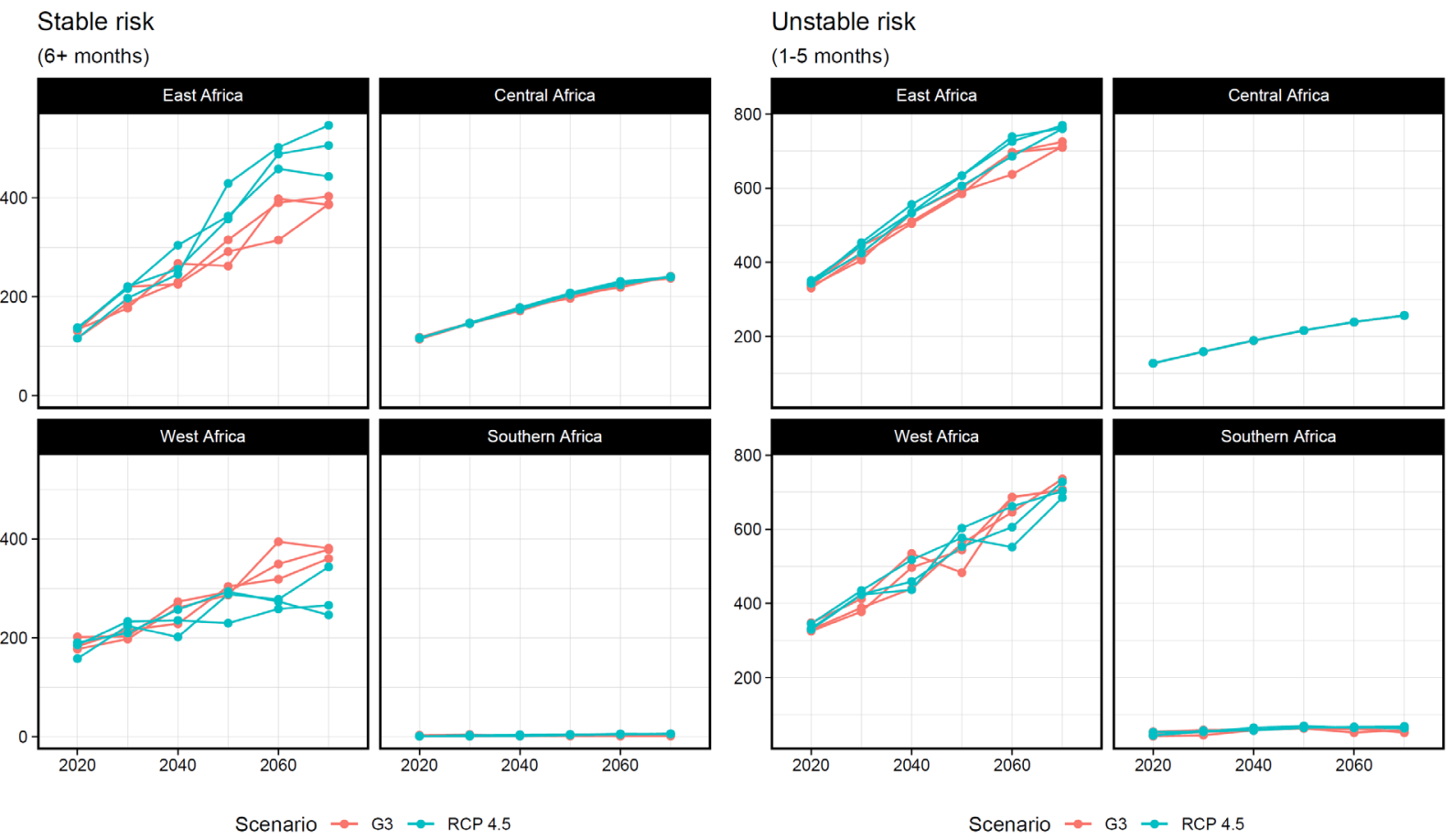
medRxiv preprint doi: https://doi.org/10.1101/2020.10.21.20217257; this version posted October 25, 2020. The copyright holder for this preprint (which was not certified by peer review) is the author/funder, who has granted medRxiv a license to display the preprint in perpetuity.

It is made available under a CC-BY-NC-ND 4.0 International license .

511 Extended Data Fig. 2. Populations at risk from vivax malaria in RCP 4.5 versus G3. 512 Transmission risk is split below, into stable risk (left) and unstable risk (right). Populations at risk 513 are reported in millions of people.
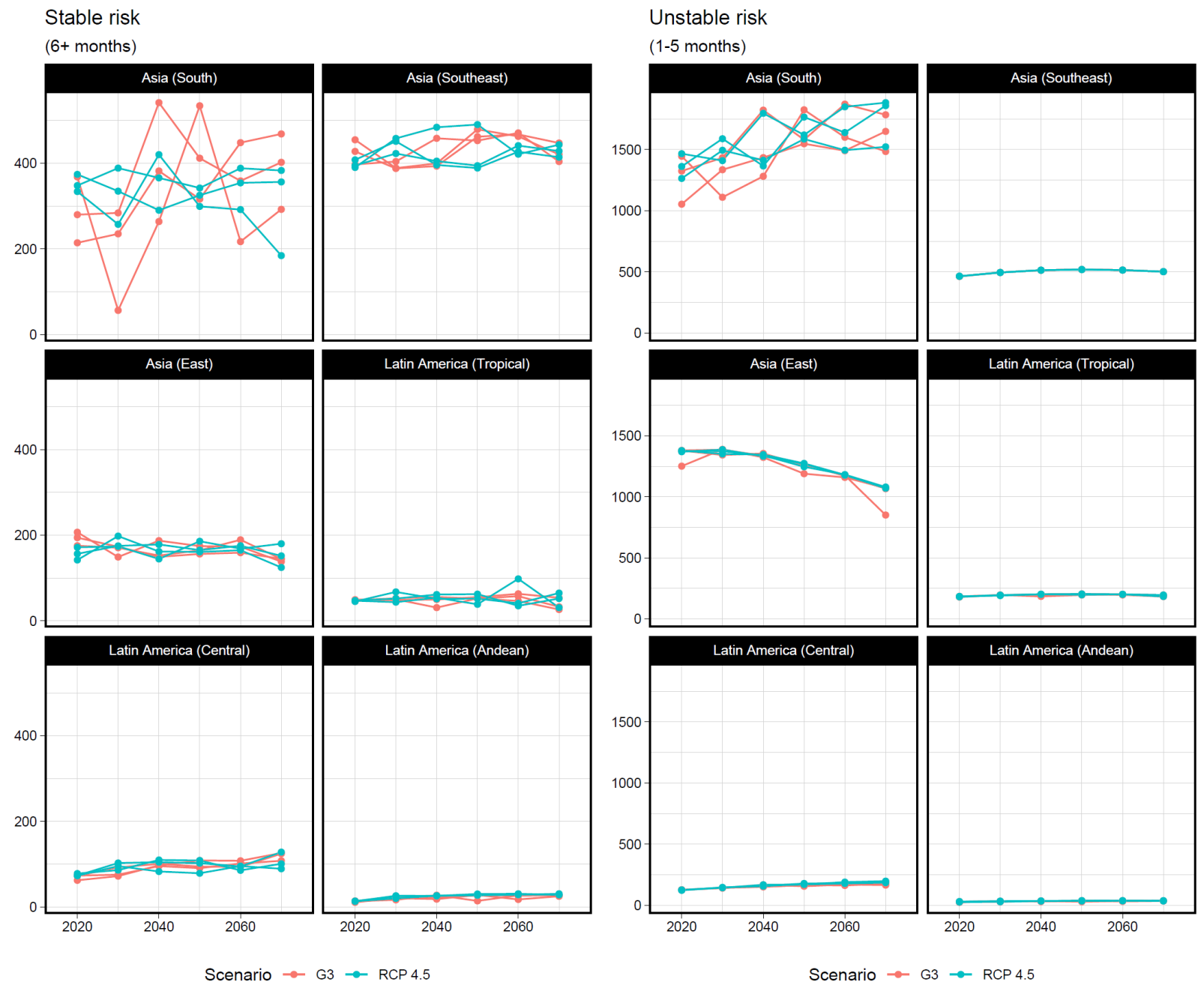
medRxiv preprint doi: https://doi.org/10.1101/2020.10.21.20217257; this version posted October 25, 2020. The copyright holder for this preprint (which was not certified by peer review) is the author/funder, who has granted medRxiv a license to display the preprint in perpetuity.

It is made available under a CC-BY-NC-ND 4.0 International license.

516 Extended Data Fig. 3: Populations at risk from falciparum malaria in GLENS versus RCP

517 8.5. Transmission risk is split below, into stable risk (left) and unstable risk (right). Populations at 518 risk are reported in millions of people.
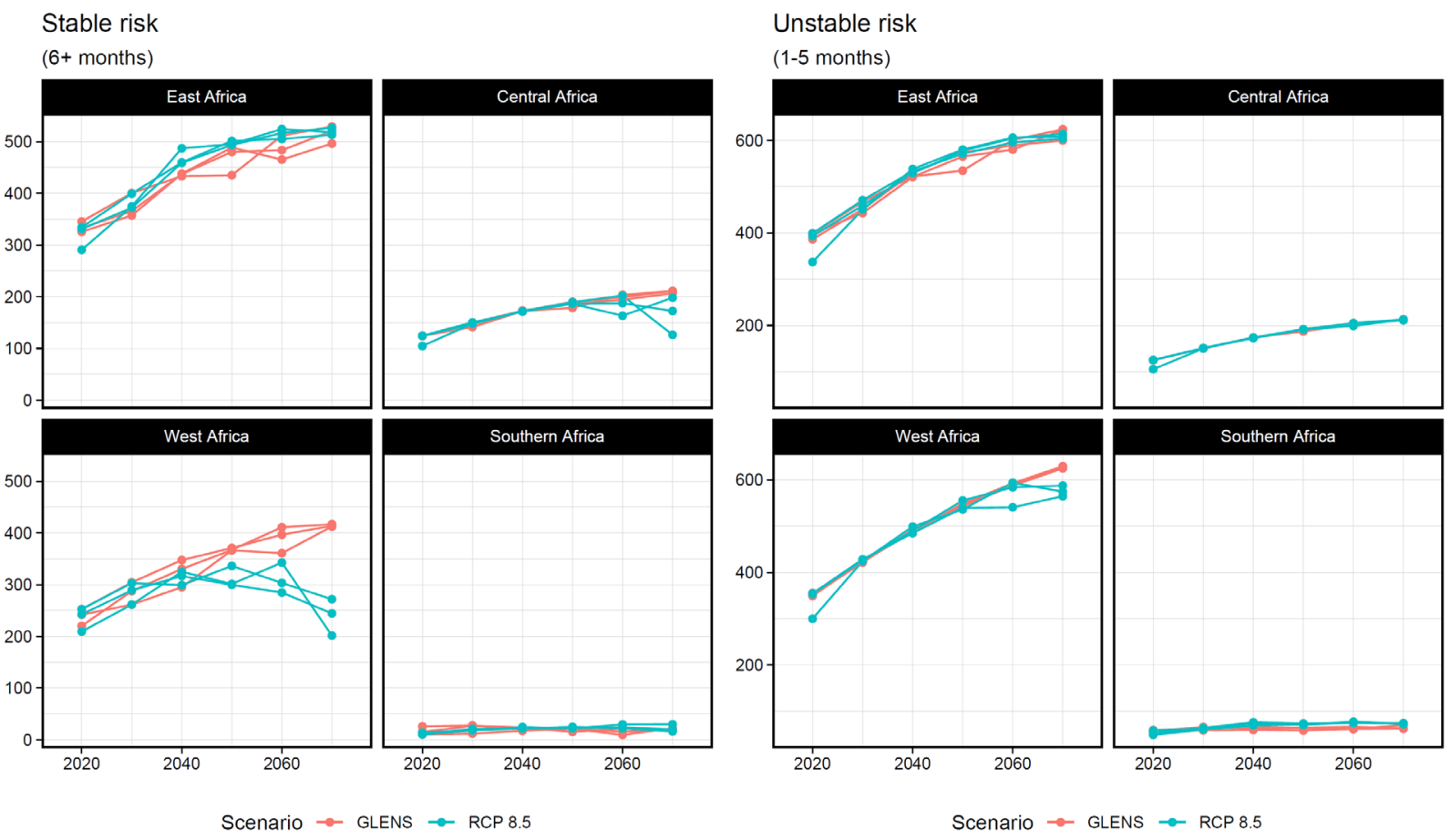
medRxiv preprint doi: https://doi.org/10.1101/2020.10.21.20217257; this version posted October 25, 2020. The copyright holder for this preprint (which was not certified by peer review) is the author/funder, who has granted medRxiv a license to display the preprint in perpetuity.

It is made available under a CC-BY-NC-ND 4.0 International license .
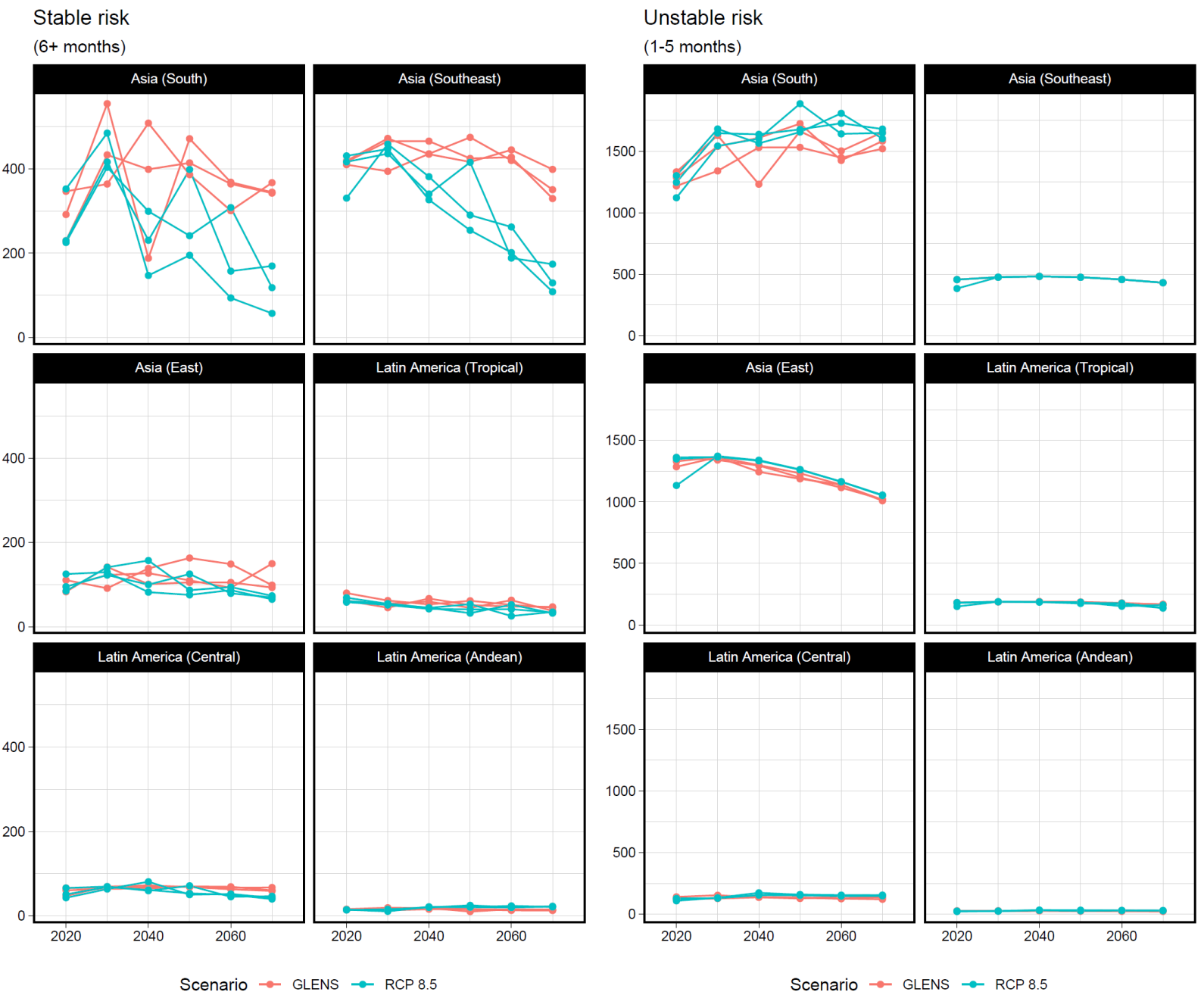


\section{References}

1. Rogelj, J. et al. Paris Agreement climate proposals need a boost to keep warming well below 2 C. Nature 534, 631-639 (2016).

2. Plazzotta, M., Séférian, R., Douville, H., Kravitz, B. \& Tjiputra, J. Land surface cooling induced by sulfate geoengineering constrained by major volcanic eruptions. Geophysical Research Letters 45, 5663-5671 (2018).

3. Proctor, J., Hsiang, S., Burney, J., Burke, M. \& Schlenker, W. Estimating global agricultural effects of geoengineering using volcanic eruptions. Nature 560, 480-483 (2018).

4. Trisos, C. H. et al. Potentially dangerous consequences for biodiversity of solar geoengineering implementation and termination. Nature Ecology \& Evolution 2, 475-482 (2018).

5. Trisos, C. H., Gabriel, C., Robock, A. \& Xia, L. in Resilience 291-303 (Elsevier, 2018).

6. Eastham, S. D., Weisenstein, D. K., Keith, D. W. \& Barrett, S. R. Quantifying the impact of sulfate geoengineering on mortality from air quality and UV-B exposure. Atmospheric Environment 187, 424-434 (2018).

7. Chen, L. \& Moore, J. C. Impact of Solar Geoengineering on Human Health from Urban Heat Stress. EGUGA 12726 (2018).

8. Carlson, C. J. \& Trisos, C. H. Climate engineering needs a clean bill of health. Nature Climate Change 8, 843-845 (2018).

9. Mordecai, E. A. et al. Thermal biology of mosquito-borne disease. Ecology Letters 22, 1690-1708 (2019).

10. Johnson, L. R. et al. Mapping the distribution of malaria: current approaches and future directions. Analyzing and modeling spatial and temporal dynamics of infectious diseases 189-209 (2014).

11. Ryan, S. J., Carlson, C. J., Mordecai, E. A. \& Johnson, L. R. Global expansion and redistribution of Aedes-borne virus transmission risk with climate change. PLoS Neglected Tropical Diseases 13, e0007213 (2019).

12. Messina, J. P. et al. The current and future global distribution and population at risk of dengue. Nature Microbiology 4, 1508-1515 (2019).

13. Ryan, S. J. et al. Warming temperatures could expose more than 1.3 billion new people to Zika virus risk by 2050. medRxiv (2020).

14. Gaythorpe, K. A., Hamlet, A., Cibrelus, L., Garske, T. \& Ferguson, N. The effect of climate change on Yellow Fever disease burden in Africa. medRxiv (2020).

15. Bhatt, S. et al. The global distribution and burden of dengue. Nature 496, 504-507 (2013).

16. Bhatt, S. et al. The effect of malaria control on Plasmodium falciparum in Africa between 2000 and 2015. Nature 526, 207-211 (2015).

17. Feachem, R. G. et al. Malaria eradication within a generation: ambitious, achievable, and necessary. The Lancet 394, 1056-1112 (2019). 
medRxiv preprint doi: https://doi.org/10.1101/2020.10.21.20217257; this version posted October 25, 2020. The copyright holder for this preprint (which was not certified by peer review) is the author/funder, who has granted medRxiv a license to display the preprint in perpetuity. It is made available under a CC-BY-NC-ND 4.0 International license .

18. Rogerson, S. J. et al. Identifying and combating the impacts of COVID-19 on malaria. BMC Medicine 18, 1-7 (2020).

19. Gutman, J. R. et al. Malaria and Parasitic Neglected Tropical Diseases: Potential Syndemics with COVID-19? The American Journal of Tropical Medicine and Hygiene tpmd200516 (2020).

20. Ryan, S. J., Lippi, C. A. \& Zermoglio, F. Shifting transmission risk for malaria in Africa with climate change: a framework for planning and intervention. Malaria Journal 19, 1-14 (2020).

21. Yamana, T. K., Bomblies, A. \& Eltahir, E. A. Climate change unlikely to increase malaria burden in West Africa. Nature Climate Change 6, 1009-1013 (2016).

22. Ryan, S. J. et al. Mapping physiological suitability limits for malaria in Africa under climate change. Vector-Borne and Zoonotic Diseases 15, 718-725 (2015).

23. Mordecai, E. A., Ryan, S. J., Caldwell, J. M., Shah, M. M. \& LaBeaud, A. D. Climate change could shift disease burden from malaria to arboviruses in Africa. The Lancet Planetary Health 4, e416-e423 (2020).

24. Ngarakana-Gwasira, E., Bhunu, C., Masocha, M. \& Mashonjowa, E. Assessing the role of climate change in malaria transmission in Africa. Malaria Research and Treatment 2016, (2016).

25. Leedale, J. et al. Projecting malaria hazard from climate change in eastern Africa using large ensembles to estimate uncertainty. Geospatial Health 11, 102-114 (2016).

26. Van Dorp, L. et al. Plasmodium vivax malaria viewed through the lens of an eradicated European strain. Molecular Biology and Evolution 37, 773-785 (2020).

27. Recht, J. et al. Malaria in Brazil, Colombia, Peru and Venezuela: current challenges in malaria control and elimination. Malaria Journal 16, 273 (2017).

28. Jaramillo-Ochoa, R. et al. Effects of political instability in Venezuela on malaria resurgence at Ecuador-Peru border, 2018. Emerging Infectious Diseases 25, 834 (2019).

29. Mordecai, E. A. et al. Optimal temperature for malaria transmission is dramatically lower than previously predicted. Ecology Letters 16, 22-30 (2013).

30. Kravitz, B. et al. Comparing surface and stratospheric impacts of geoengineering with different SO2 injection strategies. Journal of Geophysical Research: Atmospheres 124, 7900-7918 (2019).

31. Kravitz, B. et al. The geoengineering model intercomparison project (GeoMIP). Atmospheric Science Letters 12, 162-167 (2011).

32. Tilmes, S. et al. CESM1 (WACCM) stratospheric aerosol geoengineering large ensemble project. Bulletin of the American Meteorological Society 99, 2361-2371 (2018).

33. Snow, R. W., Guerra, C. A., Mutheu, J. J. \& Hay, S. I. International funding for malaria control in relation to populations at risk of stable Plasmodium falciparum transmission. PLoS Medicine 5, e142 (2008).

34. Ebi, K. L. et al. Climate suitability for stable malaria transmission in Zimbabwe under different climate change scenarios. Climatic Change 73, 375 (2005). 
35. Lainhart, W. et al. Epidemic and non-epidemic hot spots of malaria transmission occur in indigenous comarcas of Panama. PLoS Neglected Tropical Diseases 10, e0004718 (2016).

36. Tilmes, S. et al. Reaching 1.5 and $2.0^{\circ} \mathrm{C}$ global surface temperature targets using stratospheric aerosol geoengineering. Earth System Dynamics 11, 579-601 (2020).

37. Smith, M. et al. Incorporating hydrology into climate suitability models changes projections of malaria transmission in Africa. Nature Communications 11, 1-9 (2020).

38. Carlson, C. J. \& Phelan, A. L. A choice between two futures for pandemic recovery. Lancet

39. Jesudason, T. New WHO road map for NTD recovery post COVID-19. The Lancet Infectious Diseases 20, 902 (2020).

40. Molyneux, D. H., Aboe, A., Isiyaku, S. \& Bush, S. COVID-19 and neglected tropical diseases in Africa: impacts, interactions, consequences. International Health (2020).

41. Ehrenberg, J. P. et al. Strategies supporting the prevention and control of neglected tropical diseases during and beyond the COVID-19 pandemic. Infectious Diseases of Poverty 9, 1-7 (2020).

42. Winickoff, D. E., Flegal, J. A. \& Asrat, A. Engaging the Global South on climate engineering research. Nature Climate Change 5, 627-634 (2015).

43. Sillmann, J. et al. Climate emergencies do not justify engineering the climate. Nature Climate Change 5, 290-292 (2015).

44. Villena, O. C., Ryan, S. J., Murdock, C. C. \& Johnson, L. R. Temperature impacts the transmission of malaria parasites by Anopheles gambiae and Anopheles stephensi mosquitoes. BioRxiv (2020).

45. Gething, P. W. et al. Modelling the global constraints of temperature on transmission of Plasmodium falciparum and P. vivax. Parasites \& Vectors 4, 92 (2011).

46. Sinka, M. E. et al. A global map of dominant malaria vectors. Parasites \& Vectors 5, 1-11 (2012).

47. Arevalo-Herrera, M. et al. Malaria in selected non-Amazonian countries of Latin America. Acta Tropica 121, 303-314 (2012).

48. Moran, A. E. et al. Assessing the global burden of ischemic heart disease: part 1: methods for a systematic review of the global epidemiology of ischemic heart disease in 1990 and 2010. Global Heart 7, 315-329 (2012). matrix architecture. Climatic Change 122, 373-386 (2014).

50. Jones, B. \& O’Neill, B. C. Spatially explicit global population scenarios consistent with the Shared Socioeconomic Pathways. Environmental Research Letters 11, 084003 (2016). 